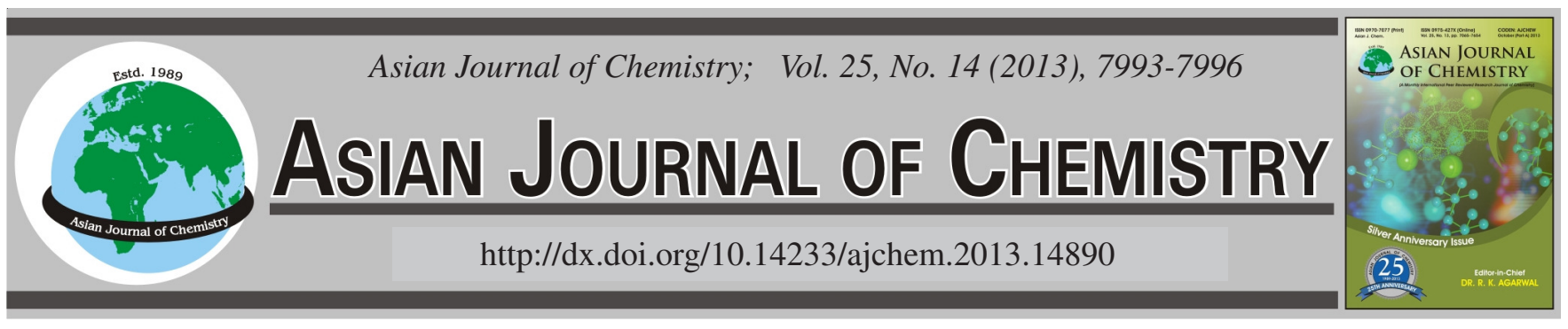

\title{
Reductive Coupling of Aromatic Aldehydes and Acetophenone Induced by $\mathrm{TiCl}_{4}-\mathrm{Al} / \mathrm{CH}_{2}(\mathrm{COOEt})_{2}$
}

Chang-Ying Song ${ }^{*}$, Shu-Xiang Wang, Wen-Hao Chu, Ji-Tai Li, Zheng Zhou, Hong-Yu Li and Zi-Qing Cao

Key Laboratory of Analytical Science and Technology, Key Laboratory of Chemical Biology of Hebei Province, College of Chemistry and Environmental Science, Hebei University, Baoding 071002, Hebei Province, P. R. China

*Corresponding author: E-mail: scy@ hbu.edu.cn

(Received: 3 December 2012;

Accepted: 29 July 2013)

AJC-13857

Induced by $\mathrm{TiCl}_{4}-\mathrm{Al} / \mathrm{CH}_{2}(\mathrm{COOEt})_{2}$ in $\mathrm{CH}_{2} \mathrm{Cl}_{2}$, some aromatic aldehydes and acetophenone can afford the corresponding 1,2-diols in

$13-91 \%$ yields with good dl-diastereoselectivities within 45-60 min at room temperature.

Key Words: Aromatic aldehydes, Pinacol coupling, Pinacol, Low valent titanium, Esters.

\section{INTRODUCTION}

Pinacol coupling reaction of carbonyl compounds is an important organic reaction to form both the new C-C bond and pinacols ${ }^{1,2}$, which has ofen been employed in total synthesis of many natural products ${ }^{3,4}$. The chiral pinacols are also the prominent auxiliaries in many asymmetric synthesis ${ }^{5-7}$. In particular, pinacol coupling has been employed as a key step in the construction of HIV-protease inhibitors ${ }^{8}$. Recent efforts have focused on the development of new reagents and reaction systems to improve the reactivity of the reagents and diastereoselectivity of the products.

Since the first report by Mukayama ${ }^{9}$ of pinacol coupling reactions mediated with a titanium reagent in 1973, low valent titanium has attracted increasing attention. Clerici and Porta ${ }^{10}$ reported pinacol coupling of aromatic aldehydes and ketones promoted by aqueous titanium trichloride in basic media, the reaction was completed in a few minutes, but the method has some limitations with respect to some aromatic aldehydes and ketones and the diastereoslectivities of the pinacols are poor. Schwartz and Barden ${ }^{11}$ reported the stereoselective pinacol coupling in aqueous media in 1996, the 1,2-diols with good yields and high diastereoselectivities were obtained. Gansäuer et al. ${ }^{12}$ reported the titanocene-catalyzed pinacol coupling of aromatic aldehydes proceeding in good yields and with high diastereoselectivity under reagent control. Enders and Ullrich ${ }^{13}$ reported asymmetric pinacol coupling of aromatic aldehydes under homogeneous conditions with $\mathrm{TiCl}_{2}$ in the presence of enantiopure amines or hydrazines afforded 1,2-diols in moderate to excellent yields with good dl-diastereoselectivities. Itoh et al. ${ }^{14}$ reported diastereoselective pinacol coupling of aldehydes promoted by monomeric titanocene(III) complex
$\mathrm{Cp}_{2} \mathrm{TiPh}$, five aromatic aldehydes gave desired pinacol in 54$96 \%$ yields within 1-4 h. Kulinkovich et al. ${ }^{15}$, reported the titanium(III) isopropoxide prepared by the reaction of titanium(IV) isopropoxide with one equivalent of the Grignard reagent transformed the aldehydes and the aromatic ketones into the corresponding pinacols in good yields.

However, in spite of their potential utility, some of the reported methods suffer from drawbacks such as longer reaction time, expensive catalysts and harsh terms. Esters can coordinate with $\mathrm{TiCl}_{4}$, so we wish to report the results on the reductive coupling of aromatic aldehydes mediated by low valent titanium using esters as ligands.

\section{EXPERIMENTAL}

Liquid aldehydes were distilled prior to use. IR spectra were recorded on a Bio-Rad FTS-40 spectrometer (KBr). MS were determined on a VG-7070E spectrometer (EI, $70 \mathrm{eV}$ ). ${ }^{1} \mathrm{H}$ NMR spectra were measured on a Bruker AVANCE 400 (400 MHz) spectrometer using TMS as the internal standard and $\mathrm{CDCl}_{3}$ as a solvent.

General procedure: A $50 \mathrm{~mL}$ two neck round bottom flask was charged with $\mathrm{CH}_{2} \mathrm{Cl}_{2}(5 \mathrm{~mL}), \mathrm{CH}_{2}(\mathrm{COOEt})_{2}$ (3 $\mathrm{mmol}), \mathrm{TiCl}_{4}(2 \mathrm{mmol})$ under a nitrogen atmosphere. The two neck round flask was put into ultrasonic bath and then $\mathrm{Al}$ powder $(4 \mathrm{mmol})$ was added. The reaction mixture was irratiated and turned into dark green immediately. After $5 \mathrm{~min}$, the mixture was removed from ultrasonic bath. Then the desired aldehyde $(\mathbf{1}, 1 \mathrm{mmol})$ in $1 \mathrm{~mL} \mathrm{CH}_{2} \mathrm{Cl}_{2}$ was added and the mixture was stirred at room temperature for a period as indicated in Table-2 (the reaction was followed by TLC). After the completion of the reaction, the resulting suspension was quenched with $10 \mathrm{~mL}$ of $10 \% \mathrm{~K}_{2} \mathrm{CO}_{3}$ and extracted with ethyl 
acetate $(3 \mathrm{~mL} \times 15 \mathrm{~mL})$. The combined organic layers were washed with saturated aqueous $\mathrm{NaHCO}_{3}$ solution and brine, dried over anhydrous magnesium sulphate for $12 \mathrm{~h}$ and filtered. Ethyl acetate was evaporated under reduced pressure to give the crude product, which was separated by column chromatography on silica (200-300 mesh), eluted with petroleum ether or a mixture of petroleum ether and diethyl ether. The authenticity of the product was established by their ${ }^{1} \mathrm{H}$ NMR, MS and IR spectral data.

2a: ${ }^{1} \mathrm{H}$ NMR: $\delta 2.52(2 \mathrm{H}, \mathrm{s}, \mathrm{OH}$, meso $), 3.18(2 \mathrm{H}, \mathrm{s}, \mathrm{OH}$, dl), $4.68(2 \mathrm{H}, \mathrm{s}, \mathrm{CH}, \mathrm{dl}), 4.82(2 \mathrm{H}, \mathrm{s}, \mathrm{CH}$, meso $), 7.11-7.32$ (20H, m, Ph-H). m/z (\%): 214 (1), 180 (7.6), 167 (12.5), 149 (6.0), 107 (93.8), 79 (100), 77 (73.8). IR (KBr, $\left.v_{\max }, \mathrm{cm}^{-1}\right)$ : 3480-3200.

2b: ${ }^{1} \mathrm{H}$ NMR: $\delta 3.03(2 \mathrm{H}, \mathrm{s}, \mathrm{OH}$, meso $), 3.07(2 \mathrm{H}, \mathrm{s}, \mathrm{OH}$, dl), $5.42(2 \mathrm{H}, \mathrm{d}, \mathrm{CH}, \mathrm{dl}), 5.67$ (2H, d, CH, meso), 7.14-7.28 (16H, m, Ph-H). m/z (\%): 282 (1), 165 (47), 141 (89), 113 (13), 107 (14), 77 (100), 51 (38). IR (KBr, $\left.v_{\max }, \mathrm{cm}^{-1}\right)$ : 35003100 .

2c: ${ }^{1} \mathrm{H}$ NMR: $\delta 2.80(2 \mathrm{H}, \mathrm{s}, \mathrm{OH}$, meso $), 3.37(2 \mathrm{H}, \mathrm{s}, \mathrm{OH}$, dl), 4.66 (2H, s, CH, dl), 4.85 (2H, s, CH, meso), 6.96-7.34 (16H, m, Ph-H). m/z (\%): 263 (1.2), 251 (1.6), 178 (4.6), 165 (4.6), 141 (100), 113 (23.8), 77 (71.0). IR (KBr, $\left.v_{\max }, \mathrm{cm}^{-1}\right)$ : 3318-3260.

2d: ${ }^{1} \mathrm{H}$ NMR: 2.96 (2H, s, OH, dl), 4.63 (2H, s, CH, dl), 7.02-7.28 (8H, m, Ph-H). m/z (\%): 276 (14), 249 (32), 155 (100), 111 (8). IR (KBr, $\left.v_{\max }, \mathrm{cm}^{-1}\right)$ : 3420-3380.

2e: ${ }^{1} \mathrm{H}$ NMR: $\delta 3.02(2 \mathrm{H}, \mathrm{s}, \mathrm{OH}$, meso $), 3.06(2 \mathrm{H}, \mathrm{s}, \mathrm{OH}$, dl), $5.31(2 \mathrm{H}, \mathrm{s}, \mathrm{CH}, \mathrm{dl}), 5.60(2 \mathrm{H}, \mathrm{s}, \mathrm{CH}$, meso $), 7.22-7.68$ (12H, m, Ph-H). m/z (\%): 352 (1), 305 (1.4), 233 (10), 175 (100), 145 (10), $111(25), 77$ (15). IR (KBr, $\left.v_{\max }, \mathrm{cm}^{-1}\right)$ : 34003320.

2f: ${ }^{1} \mathrm{H}$ NMR: $\delta 2.32\left(6 \mathrm{H}, \mathrm{s}, \mathrm{CH}_{3}, \mathrm{dl}\right), 4.69(2 \mathrm{H}, \mathrm{s}, \mathrm{CH}, \mathrm{dl})$, 7.04-7.09 (16H, m, Ph-H). m/z (\%): 242 (1.2), 195 (6), 121 (100), 107 (12), 77 (13). IR (KBr, $\left.v_{\max }, \mathrm{cm}^{-1}\right): 3450-3280 \mathrm{~cm}^{-1}$.

2g: ${ }^{1} \mathrm{H}$ NMR: $\delta 3.75\left(6 \mathrm{H}, \mathrm{s}, \mathrm{CH}_{3} \mathrm{O}, \mathrm{dl}\right), 3.79\left(6 \mathrm{H}, \mathrm{s}, \mathrm{CH}_{3} \mathrm{O}\right.$, meso), 5.13 (2H, s, CH, dl), 5.34 (2H, s, CH, meso) 6.85-7.25 $(16 \mathrm{H}, \mathrm{m}, \mathrm{Ph}-\mathrm{H}) \mathrm{ppm}$. Anal. calcd. (\%) for $\mathrm{C}_{16} \mathrm{H}_{18} \mathrm{O}_{4}$ : C 70.06, H 6.61; found (\%) C 70.02, H 6.63. IR ( $\left.\mathrm{KBr}, \mathrm{v}_{\max }, \mathrm{cm}^{-1}\right)$ : 3640$3130 \mathrm{~cm}^{-1}$.

2h: ${ }^{1} \mathrm{H}$ NMR: $\delta 4.59(2 \mathrm{H}, \mathrm{s}, \mathrm{CH}, \mathrm{dl}), 4.67(2 \mathrm{H}, \mathrm{s}, \mathrm{CH}$, meso), $5.96\left(4 \mathrm{H}, \mathrm{s}, \mathrm{CH}_{2}, \mathrm{dl}\right), 6.06\left(4 \mathrm{H}, \mathrm{s}, \mathrm{CH}_{2}\right.$, meso $), 6.56-$ 6.81 (12H, m, Ph-H). m/z (\%): 302 (1), 284 (2.5), 268 (5.0), 255 (11.8), 151 (100), 123 (32), 93 (77.1), 65 (39.0). IR (KBr, $\left.v_{\max }, \mathrm{cm}^{-1}\right): 3600-3100 \mathrm{~cm}^{-1}$.

2j: ${ }^{1} \mathrm{H}$ NMR: $\delta 1.51\left(6 \mathrm{H}, \mathrm{s}, \mathrm{CH}_{3}, \mathrm{dl}\right), 1.59\left(6 \mathrm{H}, \mathrm{s}, \mathrm{CH}_{3}\right.$, meso), 2.30 (2H, s, OH, meso), 2.60 ( $2 \mathrm{H}, \mathrm{s}, \mathrm{OH}, \mathrm{dl}), 7.20-$ $7.26(20 \mathrm{H}, \mathrm{m}, \mathrm{Ph}-\mathrm{H}) \mathrm{ppm} . \mathrm{m} / \mathrm{z}(\%): 225$ (4), 206 (4), 181 (32), 165 (9), 121 (100), 105 (12), 77 (11), 43 (80). IR (KBr, $\left.v_{\max }, \mathrm{cm}^{-1}\right): 3600-3100 \mathrm{~cm}^{-1}$.

\section{RESULTS AND DISCUSSION}

The effect of different esters on the benzaldehyde were investigated (Table-1). As shown in Table-1, the coupling of benzaldehyde mediated by $\mathrm{TiCl}_{4}$ - $\mathrm{Al}$ using different esters as ligands was carried out in good yields for a short time. For example, using ethyl acetate (Entry 1), diethyl oxalate (Entry 3), diethyl butanedioate (Entry 5), diethyl (o-)phthalate (Entry 6),
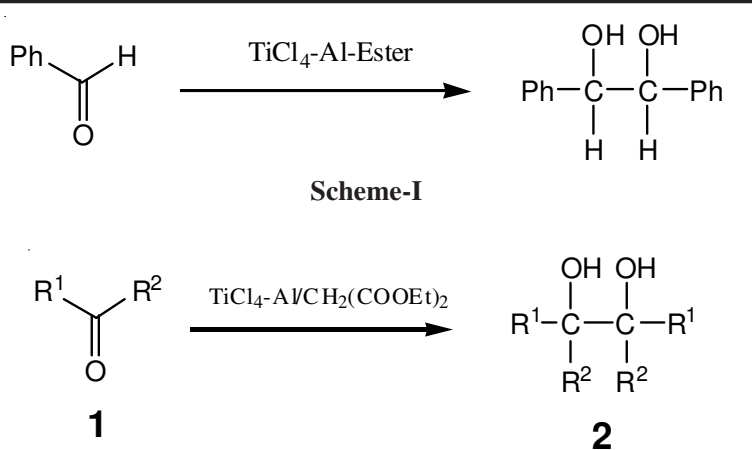

Scheme-II

dibutyl (o-)phthalate (Entry 7), diethyl camphorate (Entry 8), diethyl malonate (Entry 9) and ethyl acetoacetate (Entry 10) as ligands under stirring at room temperature within 40-50 min, 1,2-diphenyl-1,2-ethanediol was obtained with 90-93\% yields.

However, the structure of esters had obvious effect on the diastereoselectivity of 1,2-diphenyl-1,2-ethanediol. When the ligand was single ester, the $\mathrm{dl} / \mathrm{mes}$ of 1,2 -diphenyl-1,2ethanediol was low. For example, when ethyl acetate, isopentyl acetate and ethyl acetoacetate were used as ligands, the $d l /$ meso of 1,2-diphenyl-1,2-ethanediol was 68/32, 66/34 and 65/ 35 , respectively. For the double ester, using diethyl oxalate, diethyl butanedioate, diethyl $o$-phthalate, dibutyl $o$-phthalate, diethyl camphorate as ligands, the $\mathrm{dl} / \mathrm{mes}$ of 1,2 -diphenyl1,2-ethanediol was 76/24, 77/23, 82/18, 83/17 and 70/30, respectively. Using diethyl malonate as ligand, the $d l / m e s o$ of 1,2-diphenyl-1,2-ethanediol was 97.4/2.6. When diethyl (trans)-butenedioate was used as ligand, the $d l / m e s o$ of 1,2diphenyl-1,2-ethanediol was 16/84.

From the results above, using $\mathrm{CH}_{2}(\mathrm{COOEt})_{2}$ as ligand, the 1,2-diphenyl-1,2-ethanediol could be obtained in high yield and good dl-diastereoselectivity. So we did a series of experiments on the pinacol coupling of aromatic aldehydes and ketones using $\mathrm{CH}_{2}(\mathrm{COOEt})_{2}$ as ligand. The results are listed in Table-2.

The coupling of some aromatic aldehydes mediated by $\mathrm{TiCl}_{4}$-Al using $\mathrm{CH}_{2}(\mathrm{COOEt})_{2}$ as ligand was carried out in good yields. For example, using the present system under stirring at room temperature for 45 and $60 \mathrm{~min}, \mathbf{2 a}$ and $\mathbf{2 d}$ were obtained with 90 and $91 \%$ yields, respectively. Whereas $2 \mathbf{a}$ and $\mathbf{2 d}$ were prepared in 50 and $71 \%$ yields, respectively with $\mathrm{TiCl}_{4-}$ $\mathrm{Al}$ in $\mathrm{Et}_{2} \mathrm{O}$ under stirring for 38 and $29 \mathrm{~h}^{16}$.

As shown in Table-2, benzaldehyde and the aromatic aldehydes with electron-withdrawing substituents in the benzene ring (1a-1e) had high reactivity in the present system. Under stirring at room temperature, 1a-1e afforded $\mathbf{2 a - 2 e}$ in 86-91\% yields within 45-60 min. In contrast, the aromatic aldehydes with electron-donating substituents in the benzene ring (1f-1i) showed lower reactivity. Compounds of $\mathbf{2 g}$ and 2h were obtained with 38 and $28 \%$ yields within $1 \mathrm{~h}$ under stirring at room temperature When $1 \mathrm{~g}$ was as substrate, trace amount of $2 \mathrm{~g}$ was obtained.

On the other hand, when the substrate were $\mathrm{C}_{6} \mathrm{H}_{5} \mathrm{COCH}_{3}$ (1j) and 4- $\mathrm{ClC}_{6} \mathrm{H}_{5} \mathrm{COCH}_{3}(\mathbf{1 k})$, the yields of the corresponding 1,2-diols were 13 and $0 \%$, respectively. The results showed that aromatic ketones had little reactivity induced by this system. 


\begin{tabular}{|c|c|c|c|c|c|}
\hline \multicolumn{6}{|c|}{$\begin{array}{c}\text { TABLE-1 } \\
\text { EFFECT OF THE STRUCTURE OF ESTER ON PINACOLIZATION OF BENZALDEHYDE }\end{array}$} \\
\hline Entry & Ester & Temperature $\left({ }^{\circ} \mathrm{C}\right)$ & Time (min) & Isolated yield (\%) & dl/meso* \\
\hline 1 & $\mathrm{CH}_{3} \mathrm{COOEt}$ & 26 & 40 & 91 & $68 / 32$ \\
\hline 2 & $\mathrm{CH}_{3} \mathrm{COOCH}_{2} \mathrm{CH}_{2} \mathrm{CH}\left(\mathrm{CH}_{3}\right)_{2}$ & 26 & 50 & 65 & $66 / 34$ \\
\hline 3 & EtOOC-COOEt & 25 & 45 & 93 & $76 / 24$ \\
\hline 4 & & 25 & 50 & 67 & $16 / 84$ \\
\hline 5 & & 27 & 45 & 91 & $77 / 23$ \\
\hline 6 & & 28 & 40 & 92 & $82 / 18$ \\
\hline 7 & & 26 & 45 & 90 & $83 / 17$ \\
\hline 8 & & 28 & 50 & 90 & $70 / 30$ \\
\hline 9 & & 25 & 45 & 90 & $97.4 / 2.6$ \\
\hline 10 & & 26 & 45 & 91 & $65 / 35$ \\
\hline
\end{tabular}

\begin{tabular}{|c|c|c|c|c|c|}
\hline \multicolumn{6}{|c|}{$\begin{array}{r}\text { TABLE- } 2 \\
\text { PINACOLIZATION OF AROMATIC ALDEHYDES AND KI }\end{array}$} \\
\hline Entry & Substrate & Temperature $\left({ }^{\circ} \mathrm{C}\right)$ & Time (min) & Yield (\%) & dl/meso* \\
\hline $\mathrm{a}$ & $\mathrm{C}_{6} \mathrm{H}_{5} \mathrm{CHO}$ & 25 & 45 & 90 & $97.4 / 2.6$ \\
\hline $\mathrm{b}$ & $2-\mathrm{ClC}_{6} \mathrm{H}_{4} \mathrm{CHO}$ & 22 & 50 & 86 & $80 / 20$ \\
\hline $\mathrm{c}$ & $3-\mathrm{ClC}_{6} \mathrm{H}_{4} \mathrm{CHO}$ & 21 & 60 & 90 & $98.7 / 1.3$ \\
\hline d & 4- $\mathrm{ClC}_{6} \mathrm{H}_{4} \mathrm{CHO}$ & 21 & 60 & 91 & $d l$ only \\
\hline $\mathrm{e}$ & $2,4-\mathrm{Cl}_{2} \mathrm{C}_{6} \mathrm{H}_{3} \mathrm{CHO}$ & 22 & 60 & 87 & $68 / 32$ \\
\hline $\mathrm{f}$ & $4-\mathrm{CH}_{3} \mathrm{C}_{6} \mathrm{H}_{4} \mathrm{CHO}$ & 20 & 60 & 73 & $d l$ only \\
\hline $\mathrm{g}$ & $2-\mathrm{CH}_{3} \mathrm{OC}_{6} \mathrm{H}_{4} \mathrm{CHO}$ & 22 & 60 & 38 & $67 / 33$ \\
\hline $\mathrm{h}$ & $3,4-\left(\mathrm{OCH}_{2} \mathrm{O}\right) \mathrm{C}_{6} \mathrm{H}_{3} \mathrm{CHO}$ & 21 & 60 & 28 & $80 / 20$ \\
\hline $\mathrm{i}$ & $4-\mathrm{CH}_{3} \mathrm{OC}_{6} \mathrm{H}_{4} \mathrm{CHO}$ & 21 & 60 & Trace & - \\
\hline $\mathrm{j}$ & $\mathrm{PhCOCH}_{3}$ & 22 & 60 & 13 & $77 / 23$ \\
\hline $\mathrm{k}$ & $\mathrm{PhCOPh}$ & 22 & 60 & 0 & - \\
\hline
\end{tabular}

Improved diastereoselectivity has been observed in the present system. When $4-\mathrm{ClC}_{6} \mathrm{H}_{4} \mathrm{CHO}(\mathbf{1 d})$ and $4-\mathrm{CH}_{3} \mathrm{C}_{6} \mathrm{H}_{4} \mathrm{CHO}$ (1f) are substrates, the $\mathrm{dl} /$ meso of the corresponding 1,2-diols were $75 / 25$ and $74 / 26$, respectively in Itoh's report ${ }^{8}$, whereas in the present system, $\mathbf{2} \mathbf{d}$ and $\mathbf{2} \mathbf{f}$ are both dl-only.

In addition, the position of substituents in the benzene ring has some effects on the $\mathrm{dl} / \mathrm{mes}$ in the system. The coupling of the aromatic aldehydes with meta- or para-position substituents in the benzene ring has high diastereoselectivities, whereas the coupling of aromatic aldehydes with ortho-position substituents in the benzene ring showed low diastereoslectivities. For example, the $d l / m e s o$ of $\mathbf{2 c}, \mathbf{2 d}$ and $\mathbf{2 f}$ were 98.7/1.3, dl-only and dl-only. However, using 2- $\mathrm{ClC}_{6} \mathrm{H}_{4} \mathrm{CHO}$ (1b), 2,4- $-\mathrm{Cl}_{2} \mathrm{C}_{6} \mathrm{H}_{3} \mathrm{CHO}(\mathbf{1 e})$ and $2-\mathrm{CH}_{3} \mathrm{OC}_{6} \mathrm{H}_{4} \mathrm{CHO}(\mathbf{1 g})$ as substrates, the $\mathrm{dl} /$ meso of the corresponding 1,2-diols were $80 / 20,68 / 32$ and $67 / 33$, respectively.

In summary, we have found an efficient and convenient method for the preparation of diastereoslective pinacols from some aromatic aldehydes by using $\mathrm{TiCl}_{4}-\mathrm{Al} / \mathrm{CH}_{2}(\mathrm{COOEt})_{2}$ in $\mathrm{CH}_{2} \mathrm{Cl}_{2}$ under stirring at room temperature. The main advantage of the present procedure is the milder reaction conditions, inexpensive catalyst and operational simplicity.

\section{ACKNOWLEDGEMENTS}

This work was supported by grants from Education Department of Hebei province (Project Z2012041), College students' innovative entrepreneurial training plan (Project 2012068) and Open Fund of Laboratory of Key Laboratory of Analytical Science and Technology of Hebei Province (Project 09265631D-6).

\section{REFERENCES}

1. G.M. Robertson, In eds.: B.M. Trost and I. Fleming, Comprehensive Organic Synthesis, Pergamon: Oxford, p. 563 (1991).

2. J.E. McMurry, Chem. Rev., 89, 1513 (1989).

3. E.J. Corey, R.L. Danheiser, S. Chandrasekaran, P. Siret, G.E. Keck and J. Gras, J. Am. Chem. Soc., 100, 8031 (1978). 
4. C.S. Swindell, W. Fan and P.G. Klimko, Tetrahedron Lett., 35, 4959 (1994).

5. J.K. Whitesell, Chem. Rev., 89, 1581 (1989).

6. C.A. Ray, T.W. Wallace and R.A. Ward, Tetrahedron Lett., 41, 3501 (2000).

7. M.B. Andrus, B.B.A. Somasekhar, E.L. Meredith and N.K. Dalley, Org. Lett., 2, 2035 (2000).

8. (a) B. Kammermeier, G. Beck, D. Jacobi and H. Jendralla, Angew. Chem., 106, 719 (1994); (b) M.T. Reetz and N. Griebenow, Liebigs Ann., 335 (1996).

9. T. Mukaiyama, T. Sato and J. Hanna, Chem. Lett., 1041 (1973).
10. A. Clerici and O. Porta, Tetrahedron Lett., 23, 3517 (1982).

11. M.C. Barden and J. Schwartz, J. Am. Chem. Soc., 118, 5484 (1996).

12. A. Gansäuer, M. Moschioni and D. Bauer, Eur. J. Org. Chem., 1923 (1998).

13. D. Enders and E.C. Ullrich, Tetrahedron: Asymm., 11, 3861 (2000).

14. Y. Yamamoto, R. Hattori, T. Miwa, Y.I. Nakagai, T. Kubota, C. Yamamoto, Y. Okamoto and K. Itoh, J. Org. Chem., 66, 3865 (2001).

15. E.A. Matiushenkov, N.A. Sokolov and O.G. Kulinkovich, Synlett, 77 (2004).

16. Y.L. Hu, Z.Y. Du, J.X. Wang, Y.S. Xi and S.J. Gu, Synth. Commun., 28, 3305 (1998). 